\title{
Sertolioma in a Canadian Husky: Relationship between Tumor, Hormones, Neurons and Skin
}

\author{
Jamile Haddad Neta', Letícia Amanda dos Santos Silva', Kátia Midori Yamanishi Shimura', \\ Rebeca Cordeiro Justino', Giovana Wingeter Di Santis² \& Maria Isabel Mello Martins²
}

\begin{abstract}
Background: Sertolioma is a slow-growing, non-invasive, firm and nodular tumor, malignant in $10 \%$ to $22 \%$ of cases and with low metastatic potential. Old age and cryptorchidism increase up to 26 times its chances of development and associates it with malignancy. Paraneoplastic syndrome, shown in $20 \%$ to $30 \%$ of the animals, is due to the aromatization of testosterone or the direct production of estrogen by tumor cells, leading to signs of feminization and bone marrow aplasia. The objective of this article is to report a case of sertolioma in a dog with dermatological characteristic symptoms, but presenting an unusual aggressive behavior, both completely reverted after castration.

Case: A 9-year-old, uncastrated, aggressive and uncontrollable Canadian Husky dog was treated at the Institutional Veterinary Hospital with parapenial volume increase and generalized alopecia. A scrotal testis of reduced size and flaccid consistency and a mass in a parapenial region of $11 \times 7.5 \times 8 \mathrm{~cm}$ in diameter, with a cystic contour, adhered to the abdominal musculature and painless to palpation were detected. Cytology of the parapenial mass presented an image compatible with seminoma or sertolioma, and the preputial smear revealed a predominance of superficial cells. Ultrasound examination showed a heterogeneous inguinal mass, with expansive cystic area, compatible with mass in retained inguinal testis. Therapeutic course consisted of bilateral orchiectomy. Ectopic testis was firm to the cut, had whitish to yellowish coloration and was surrounded by a tunica containing $200 \mathrm{~mL}$ of serosanguinolent liquid. The histology of the mass revealed sertolioma-compatible cell characteristics, with cell proliferation circumvented by fibrous connective tissue forming poorly delimited lobes, moderate polymorphism with elongated cells, arranged in a palisade at the periphery of the lobes, vacuolated eosinophilic cytoplasm and vesiculous round nuclei. The unretained testicle revealed signs of atrophy. After surgery the patient showed a progressive improvement of the dermatological symptoms. However, what most caught the attention was the change in aggressive behavior, and fifteen days after surgery the animal was extremely docile and easily restrained during the clinical examination.

Discussion: Hyperesthyrogenism due to sertolioma results from: 1) direct synthesis of estrogen by neoplastic tumor cells 2) increase in metabolism by central conversion (testicular cells) or peripheral hepatocytes, myocytes, adipocytes, hair follicles and neural tissue) androgens into estrogen through the aromatization of testosterone and 3) androgen and estrogen rate imbalance. Testosterone is considered responsible for the aggressive behavior in males, evidenced by the decrease of this behavior when the testicles are removed, and by the reinstallation of this behavior when the hormonal replacement is done. However, research on mice showed that estrogen-sensitive regulatory pathways also play a role in promoting this behavior. Although practically undetectable in male circulation, its presence stems from in vivo synthesis from the aromatization of testosterone, and it is this local estrogen, peripherally synthesized in the brain, that would be responsible for the control of dimorphic behaviors in males. The importance of the estrogen signaling pathway in aggression has also been reported in a study in knockout mice for estrogen receptors, in which males rarely exhibited aggressiveness. Such information is sufficient to support the hypothesis that the disappearance of the aggressiveness of the reported animal was obtained due to castration and correction of hyperestrogenism, showing the importance of including it as an important cause of aggressive behavior in uncastrated male dogs.
\end{abstract}

Keywords: aggressive behavior, alopecia, canine, testicular tumours.

DOI: $10.22456 / 1679-9216.93607$

Received: 22 April 2019

Accepted: 25 July 2019

Published: 31 August 2019

${ }^{1}$ Programa de Pós-graduação em Ciência Animal (PPGCA) \& ${ }^{2}$ Departamento de Clínicas Veterinárias, Universidade Estadual de Londrina (UEL), Londrina, PR, Brazil. CORRESPONDENCE: M.I.M. Martins [imartins@uel.br]. Departamento de Clínicas Veterinárias, Centro de Ciências Agrárias - UEL. CEP 86057-970 Londrina, PR, Brazil. 


\section{INTRODUCTION}

Sertolioma is a Sertoli-derived cell tumor, slow-growth and non-invasive, firm and nodular at palpation, malignant in $10 \%$ to $22 \%$ [12,22] with low metastasis potential [2,9]. The main risk factors are advanced age and cryptorchidism, which increase up to 26 times the chances of tumoral development and associate it with malignancy $[14,18,28,30]$. Sertolioma is recognized for causing a paraneoplastic syndrome, due to hyperestrogenism manifested in 20 to $30 \%$ of the animals, resulting from the testosterone aromatization or the direct production of estrogen by tumor cells and whose signs are manifested by feminization syndrome and bone marrow aplasia [8,33]. Dermatologically, it is characterized by epidermal thinning, symmetric bilateral alopecia of slow, progressive and non-pruritic evolution, hair fragility and hyperpigmentation [12]. The aim of this article is to report a curious case of canine sertolioma with dermatological and also behavioral symptoms, manifested by aggressiveness, with complete reversal of symptoms after surgical treatment of testicular excision.

\section{CASE}

A 9-year-old Canadian Husky dog was treated at the Institutional Veterinary Hospital with a progressive parapenian enlargement of the left side of progressive growth, identified during the bath, with four months evolution and development of generalized alopecia except in head and extremities (Figure 1). The animal was not neutered, had no coverage history, showed interest in females in heat and did not attract males. It was also reported by those responsible that it had extremely aggressive behavior and uncontrollable nature, to the point of administering oral medication with the aid of a long object because of having suffered bites in restraintment attempts. On physical examination, a scrotal testis of small size and flaccid consistency and volume increase in a left parapenial region of $11 \times 7.5 \times 8 \mathrm{~cm}$ in diameter, with a cystic contour, adhered to the abdominal musculature and painless to palpation was detected. The animal had epidermal thinning, intense hair fragility, more prominent in the cervical region and ventral abdomen, with areas of gereralized hyperpigmentation and epilation. Fine needle aspiration cytology analysis of the parapenial mass was compatible with seminoma and/or sertolyoma. Predominance of superficial cells was observed on preputial smear cytology (Figure 2), similar to vaginal cytology of estrus females. Hemato- logical and biochemical tests were normal. The patient was referred for ultrasonographic examination of the parapenial mass and metastasis examination. The results revealed a heterogeneous mass, with an expansive cystic area, compatible with retained inguinal testicle mass, as well as sublumbar lymphnode increase and prostatic enlargement with microcavitations compressing the rectum and the prostatic urethra. The therapeutic course was bilateral orchiectomy under general inhalation anesthesia (Figure 3). Immediately after surgery, testis were sent for histopathological analysis. Postoperative treatment consisted of oral antibiotic therapy with cefalexin $\left(\text { Celesporin }{ }^{\circledR}\right)^{1}$ at $30 \mathrm{mg} / \mathrm{kg}$ every $8 \mathrm{~h}$ for 10 days, a non-steroidal anti-inflammatory drug $\left(\text { Maxicam }^{\circledR}\right)^{1}$ at 0.1 $\mathrm{mg} / \mathrm{kg}$ every $24 \mathrm{~h}$ for three days and systemic analgesic therapy with tramadol hydrochloride $\left(\text { Cronidor }^{\circledR}\right)^{2}$ at 3 $\mathrm{mg} / \mathrm{kg}$ every $8 \mathrm{~h}$ for 3 days, as well as cleaning of surgical wound with $0.9 \%$ (Sodium Chloride $0.9 \%)^{3}$ and topical chlorhexidine (Riohex $0.2 \%)^{4}$, every $12 \mathrm{~h}$ for 10 days and use of Elizabethan collar $24 \mathrm{~h}$ a day for 10 days to avoid self-traumatism. Macroscopic evaluation showed that ectopic testis $(6.5 \times 4.5 \times 1.5 \mathrm{~cm})$ was firm to the cut, whitish to yellowish coloration and was wrapped in a tunic containing $200 \mathrm{~mL}$ of serosanguinolent liquid. On microscopy it was identified proliferation of neoplastic Sertoli cells contorted by fibrous connective tissue forming poorly delimited lobes. This cell population had moderate polymorphism, with elongated cells, arranged in palisade at the periphery of the lobes, with vacuolated eosinophilic cytoplasm and vesiculous round nuclei and three mitotic figures in ten fields of greater magnification. Through this findings, the diagnosis of sertolioma was established (Figure 4). Histology of the right testicle revealed germ cell decrease, degeneration of Sertoli cells in seminiferous tubes and thickening of the interstitium, demonstrating testicular atrophy. During four months after the surgical procedure, the patient was re-evaluated fortnightly, showing a progressive improvement of the dermatological lesions, with hair growth and reduction of hyperpigmentation (Figure 5). However, what was most striking was the absence of aggressive behavior, because fifteen days after surgery the animal was docile and easily restrained during the clinical examination.

\section{DISCUSSION}

The clinical case is in agreement with literature regarding the affected species, sex, age, clinical dermatological signs, uncastrated state with presence of 


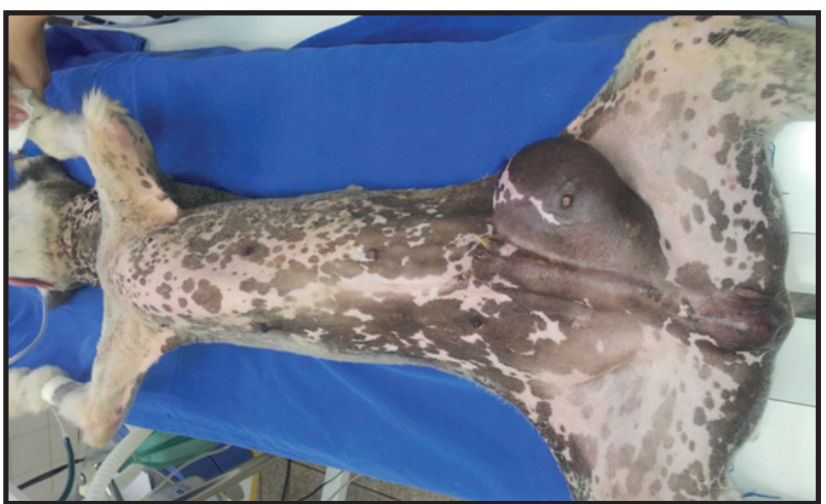

Figure 1. General appearance of a Canadian Husky dog in dorsal decubitus moments before surgical procedure. Note the large left parapenial mass and atrophied right testicle. Observe the hair thinning, generalized hyperpigmentation and macular melanosis, markedly on the ventral abdomen. [Source: personal archive].

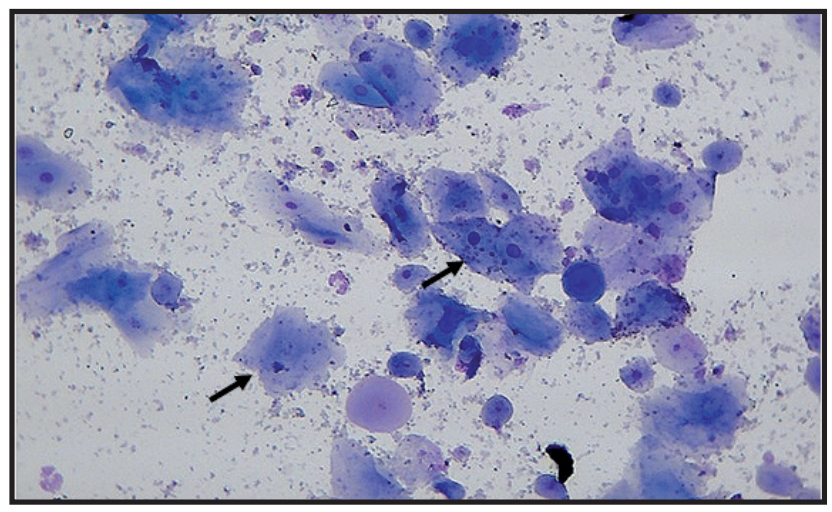

Figure 2. Cytological image from preputial smear. Observe the predominance of superficial cells (arrows) [Fast Panotic Stain (Laborclin ${ }^{\circledR}$ ); 400x]. [Source: personal archive].

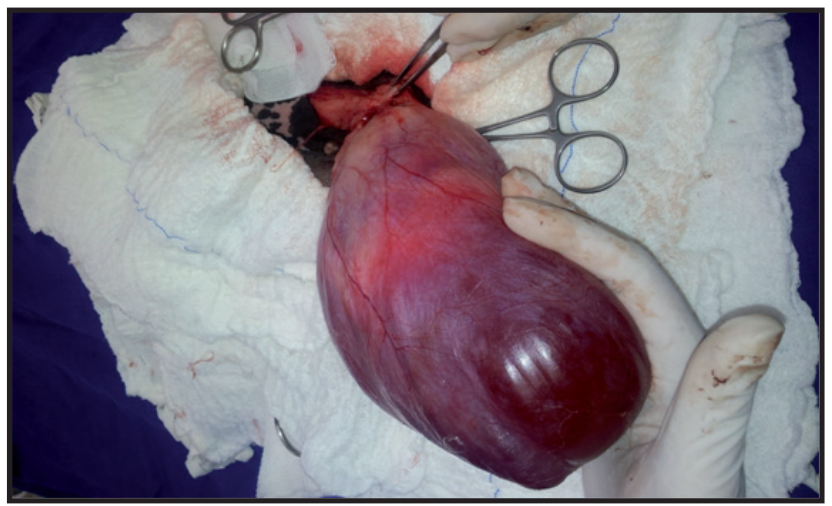

Figure 3. Macroscopic image of the left ectopic testicle at the moment of surgery, presenting $11 \times 7.5 \times 8 \mathrm{~cm}$ in diameter, surrounded by a richly vascularized capsule with cystic content. [Source: personal archive].

cryptorchidism and absence of metastasis [20,21,27]. The dense coat and the aggressive behavior made the owner's visualization of parapenial volume increase difficult, which was only observed during the animal bath. This fact is also in accordance with literature, since most of these tumors are accidental findings, usually at the moment of physical examination or imaging tests [12].

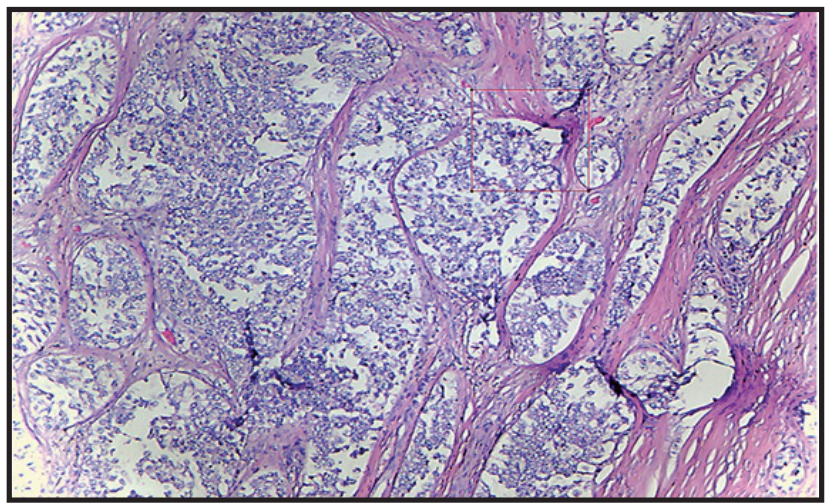

Figure 4. Microscopic appearance of ectopic testis, compatible with sertolioma. Note lobular pattern delimited by septa of thick connective tissue and tumor cells vacuolization, moderate polymorphism with elongated cells, arranged in palisade at the periphery of the lobes (HE, 100x). [Source: personal archive].

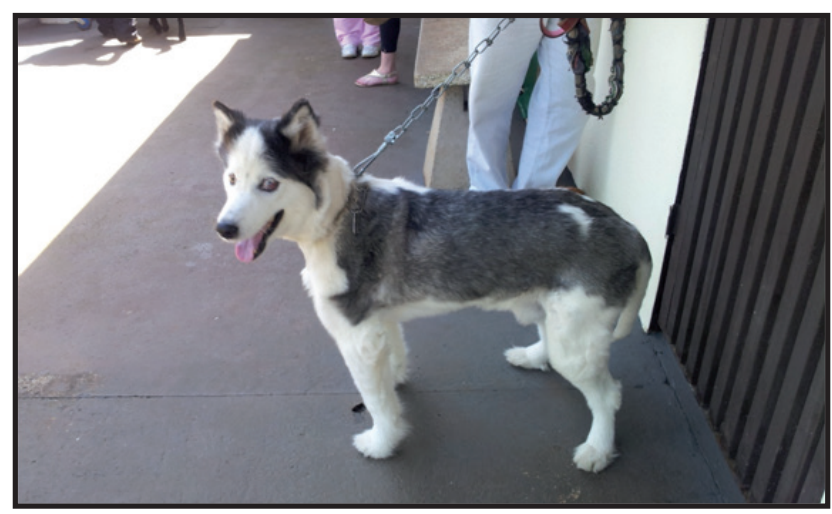

Figure 5. Patient on clinical reassessment two months after the orchiectomy, presenting remarkable reepilation, docile countenance and without use of muzzle to remain in the waiting room. [Source: personal archive].

Sertolioma can cause a paraneoplastic syndrome due to hyperestrogenism that occurs in 20 to $30 \%$ of the animals. Hormonal production is proportional to the tumor size and comes from: 1) direct synthesis of estrogen by neoplastic tumor cells 2) increased metabolism by central (by testicular cells) or peripheral (by hepatocytes, myocytes, adipocytes, hair follicles and neural tissue) conversion of androgens in estrogens, through aromatization of testosterone and 3) of the androgen and estrogen rate imbalance [12,31]. Dogs with Sertoli cells tumor have significantly higher concentrations of estradiol and immunoreactivity to inhibin, with decreased FSH concentration compared to normal dogs, both in peripheral venous blood and in testicular blood, whereas the testosterone concentrations are decreased, also in peripheral and testicular venous blood [28]. The serum $17-\beta$-oestradiol concentration, despite being recommended, was not performed in the animal, a fact that did not compromise the diagnosis, since it can be present within normal concentrations due to the individual variations observed among affected dogs [17]. The anti-mullerian hormone 
(AMH), expressed in Sertoli cells, has been shown to be a specific biomarker in humans and, although not yet widespread and commercially available, its use may be promising in the immunohistochemical diagnosis of canine sertolioma [16]. The feminization syndrome due to hyperestrogenism is observed in 25 to $50 \%$ of the animals, and is characterized by gynecomastia, galactorrhea, attraction of male dogs by the affected ones, mimicking female in heat, female-like urinary posture, squamous metaplasia of the prostate, pendular prepuce, penile and contralateral atrophy of the nonneoplastic testis, decreased libido and oligospermia, resulting from the inhibition of GnRH, FSH and $\mathrm{LH}$ secretion by the feedback loop of the hypothalamicpituitary-gonadal axis $[8,12,15,31]$. Of these signs, the only one presented by the case reported was contralateral atrophy of the non-neoplastic testis. However, the dermatological signs presented are strongly associated with those of literature: epidermal thinning and symmetric bilateral alopecia of slow and progressive, non-itchy growth, beginning in the perineal and genital regions and spreading to the abdomen, thorax, flank and neck $[12,33]$. Hair can be easily removed and there is commonly chronicity-related hyperpigmentation as well as macular melanoma in the inguinal, perineal, and genital region, and linear preputial dermatosis, extending from the foreskin to the scrotum and is considered a highly suggestive neoplastic testicular [33]. As in this case the main suspected of dermatological and behavioral alterations was hyperestrogenism secondary to sertolioma, a cytological examination was performed from the preputial smear, with a predominance of superficial cells. According to Dreimanis [11], the preputial smear has high sensitivity and specificity to testicular tumors diagnosis that produce estrogen, with $80 \%$ of superficial or cornified cells predominance. Results of hematological and biochemical exams were normal, similar to those found by Carreira [4], demonstrating that despite the intense dermatological alteration due to hyperestrogenism, the patient did not show signs of hypoplasia or bone marrow aplasia. Myelotoxicity, which is responsible for the worsening prognosis, is due to excess of estrogen interfering on differentiation of hematopoietic stem cells, altering the iron utilization by erythrocyte precursors and inhibiting the production of erythrocyte stimulating factor in circulation [10]. Initially, bone marrow estrogenic intoxication induces an increase in granulocytopoiesis and reduction of megakaryocytes and erythroid elements, leading to neutrophilia with left-sided deviation, thrombocytopenia and anemia. The aplasia of cell lines and the development of pancytopenia begins after the development of this initial condition [10]. The findings of physical, ultrasonographic and cytological examination allowed the presumptive diagnosis of seminoma and sertolioma, but the conclusive diagnosis was only possible by histopathological examination, considered as the most important tool in the diagnostic confirmation [12]. Microscopic findings, such as moderate polymorphism with proliferation of elongated cells circumvented by abundant fibrous tissue, arranged palisade at the periphery of the lobes and few mitotic figures, were compatible with sertolioma [5,13,19,24]. For four months after the surgical procedure, the patient was re-evaluated biweekly, showing a progressive improvement of the dermatological condition with hair growth and decreased hyperpigmentation (Figure 5). However, what was most striking was the extreme change in aggressive behavior, and fifteen days after surgery the animal was docile and easily restrained during the clinical examination.

Traditionally, testosterone and estrogen are considered male and female sex hormones, respectively [32]. In fact, testosterone masculinizes the neural circuits in neonate rodents and acts on these pathways in adult males to allow the display of dimorphic behaviors [29]. Its effects, mediated by receptor activation, are essential for the display of male behaviors in most vertebrates, such as aggression and libido, and are non-existent in mutant mice for this receptor [26].

Aggression among male rats is a form of social behavior in which adult males struggle to establish dominance relations. Testosterone testicular removal by castration results in decreased aggression as well as a loss of dominance [3], and the replacement of this hormone reinstalls such behaviors [23]. Several studies have documented the medial pre-optic area and/or the medial hypothalamus as sites containing the testosterone-sensitive neural circuits that modulate aggression, since lesions in these areas have resulted in this behavioral suppression [1]. Although testosterone undoubtedly plays an important role in the male's aggressive behavior, studies in rats have shown that estrogen-sensitive regulatory pathways also play a role in promoting this behavior [6]. This fact seems counterintuitive, since this ovarian hormone 
is practically undetectable in the male circulation. Its presence is due to in vivo synthesis from testosterone or androgens by a reaction catalyzed by aromatase, an enzyme expressed in encephalic cells and essential for the conversion of circulating testosterone to estrogen. It is this local estrogen, peripherally synthesized in the brain, which would be behind the control of the dimorphic behaviors in males [35].

The importance of the estrogen signaling pathway in aggression was also reported in a study in knockout mice for estrogen receptors, in which males rarely exhibited aggressiveness among themselves [25]. In addition, increased aromatase activity was detected in the amygdala of more aggressive mice during early ontogenesis [7]. The participation of estrogen in aggressive behavior was also implicated in other vertebrates, such as singing birds, showing that inhibition of aromatase activity abolished male aggressive behavior during the non-breeding season [34]. Such information may support the hypothesis that aggressiveness disappearance of the patient was obtained by the castration and correction of hyperestrogenism. However, complementary studies are still essential to understand if only the estrogen synthesized peripherally in the brain from the action of aromatase would be responsible for the aggressive behavior, or if its testicular synthesis from the sertolioma would also be able to stimulate the same neural pathways responsible for such behavior. In any case, this report proposes the importance of considering this hormonal disorder as a possible cause of aggressive behavior in uncastrated male dogs with signs of testicular enlargement.

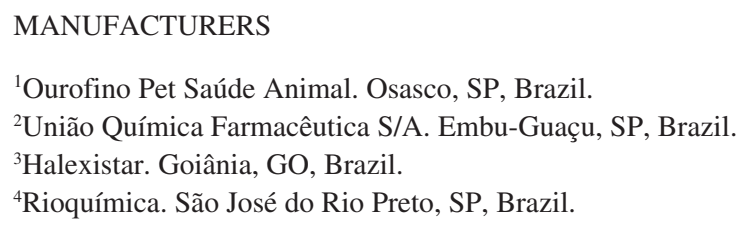

Declaration of interest. The authors report no conflicts of interest. The authors alone are responsible for the content and writing of the paper.

\section{REFERENCES}

1 Albert D.J., Dyson E.M., Walsh M.L. \& Gorzalka B.B. 1987. Intermale social aggression in rats: Suppression by medial hypothalamic lesions independently of enhanced defensiveness or decreased testicular testosterone. Physiology \& Behavior. 39(6): 693-698.

2 Amann R.P. 1970. Sperm Production Rates. In: Johnson A.D., Gomes W.R. \& Vandermark N.L. (Eds). The Testis. v.1. New York: Academic Press, pp.433-482.

3 Barfield R.J., Busch D.E. \& Wallen K. 1972. Gonadal influence on agonistic behavior in the male domestic rat. Hormones and Behavior. 3(3): 247-259.

4 Carreira V.S., Langohr I.M., Ferrari H.F. \& Luvizotto M.C.R. 2012. Pathology in Practice: Sertoli cell tumor. Journal of the American Veterinary Medical Association. 241(1): 55-57.

5 Ciaputa R., Nowak M., Kiełbowicz M., Antończyk A., Błasiak K. \& Madej J.A. 2012. Seminoma, Sertolioma, and Leydigoma in Dogs: Clinical and Morphological Correlations. Bulletin of the Veterinary Institute in Pulawy. 56(3): 361-367.

6 Cologer-Clifford A., Simon N.G., Richter M.L., Smoluk S. \& Lu S. 1998. Androgens and estrogens modulate 5-HT1A and 5-HT1B agonist effects on aggression. Physiology \& Behavior. 65(4-5): 823-828.

7 Compaan J.C., Hutchison J.B., Wozniak A., De Ruiter A.J.H. \& Koolhaas J.M. 1994. Brain aromatase activity and plasma testosterone levels are elevated in aggressive male mice during early ontogeny. Developmental Brain Research. 82(1-2): 185-192.

8 Cooley C.L. \& Waters J. 2001. Tumours of the male reproductive system. In: Withrow S.J. \& MacEwen E.G. (Eds). Small Animal Clinical Oncolog. 3rd. edn. Philadelphia: Saunders, pp.480-482.

9 Crow S.E. 1980. Neoplasms of the reproductive organs and mammary glands of the dog. In: Morrow D.A. (Ed). Current Therapy in Theriogenology. Philadelphia: Saunders, pp.640-646.

10 De Bosschere H. \& Deprest C. 2010. Estrogen-induced pancytopenia due to a Sertoli cell tumor in a cryptorchid Beauceron. Vlaams Diergeneeskundig Tijdschrift. 79(4): 292-296.

11 Dreimanis U., Vargmar K., Falk T., Cigut M. \& Toresson L. 2012. Evaluation of preputial cytology in diagnosing oestrogen producing testicular tumours in dogs. Journal of Small Animal Practice. 53(9): 536-541.

12 Feldman E.C.\& Nelson R.W. 2004. Disorders of the testes and epididymides. In: Canine and Feline Endocrinology and Reproduction. 3rd edn. Philadelphia: Saunders, pp.961-976. 
13 Foster R.A. 2018. Sistema Reprodutor Masculino. In: Zachary J.F. (Ed). Bases da Patologia em Veterinária. 6.ed. Rio de Janeiro: Elsevier, pp.1194-1222.

14 Hayes Jr. H.M., Wilson G.P., Pendergrass T.W. \& Cox V.S. 1985. Canine cryptorchism and subsequent testicular neoplasia: case-control study with epidemiologic update. Teratology. 32(1): 51-56.

15 Hedlund C.S. 2005. Cirurgia dos sistemas reprodutivo e genital. In: Fossum M.T.W. \& Duprey L.P. (Eds). Cirurgia de Pequenos Animais. 2.ed. São Paulo: Roca, pp.659-662.

16 Holst B.S. \& Dreimanis U. 2015. Anti-Müllerian hormone: a potentially useful biomarker for the diagnosis of canine Sertoli cell tumours. BMC Veterinary Research. 11: 166.

17 Jericó M.M. 2016. Dermatoses relacionadas aos hormônios gonadais. In: Larsson C.E. \& Lucas R. (Eds). Tratado de Medicina Externa - Dermatologia Veterinária. São Caetano do Sul: Interbook Editorial Ltda., pp.599-610.

18 Johnson C.A. 2006. Distúrbios do sistema reprodutivo. In: Nelson R.W. \& Couto C.G. (Eds). Medicina Interna de Pequenos Animais. 3.ed. Rio de Janeiro: Roca, pp.811-911.

19 Kennedy P.C., Cullen J.M., Edwards J.F., Goldschmidt M.H., Larsen S., Munson L. \& Nielsen S. 1998. Histological classifications of tumors of the genital system of domestic animals. In: World Health Organization International Histological Classification of Tumors of Domestic Animal. Washington D.C.: Armed Forces Institute of PathologyAmerican Registry of Pathology, pp.17-18.

20 Liao A.T., Chu P., Yeh L. \& Liu C.H. 2009. 12-year retrospective study of canine testicular tumors. The Journal of Veterinary Medical Science. 71(7): 919-923.

21 McEntee M.C. 2002. Reproductive Oncology. Clinical Techniques in Small Animal Practice. 17(3): 133-149.

22 Morris J. \& Dobson J. 2001. Genital Tract. In: Small Animal Oncology. Oxford: W.B. Saunders, pp.174-177.

23 Motelica-Heino I., Edwards D.A. \& Roffi J. 1993. Intermale aggression in mice: does hour of castration after birth influence adult behavior? Physiology \& Behavior. 53(5): 1017-1019.

24 Nascimento E.F., Santos R.L. \& Edwards J. 2016. Sistema Reprodutivo Masculino. In: Santos R.L. \& Alessi A.C. (Eds). Patologia Veterinária. 2.ed. Rio de Janeiro: Roca, pp.813-820.

25 Ogawa S., Eng V., Taylor J., Lubahn D.B., Korach K.S. \& Pfaff D.W. 1998. Roles of estrogen receptor- $\alpha$ gene expression in reproduction-related behaviors in female mice. Endocrinology. 139(12): 5070-5081.

26 Ohno S., Geller L.N. \& Lai E.V.Y. 1974. Tfm mutation and masculinization versus feminization of the mouse central nervous system. Cell. 3(3): 235-242.

27 Ortega-Pacheco A., Rodriguez-Buenfil J.C., Segura-Correa J.C., Bolio-Gonzalez M.E., Jiménez-Coello M. \& Linde Forsberg C. 2006. Pathological conditions of the reproductive organs of male stray dogs in the tropics: prevalence, risk factors, morphological findings and testosterone concentrations. Reproduction in Domestic Animals. 41(5): 429-437.

28 Peters M.A.J., De Jong F.H., Teerds K.J., De Rooij D.G., Dieleman S.J. \& Van Sluijs F.J. 2000. Ageing, testicular tumours and the pituitary-testis axis in dogs. Journal of Endocrinology. 166(1): 153-161.

29 Phoenix C.H., Goy R.W., Gerall A.A. \& Young W.C. 1959. Organizing action of prenatally administered testosterone propionate on the tissues mediating mating behavior in the female guinea pig. Endocrinology. 65(3): 369-382.

30 Quartuccio M., Marino G., Garufi G., Cristarella S. \& Zanghi A. 2012. Sertoli cell tumors associated with feminizing syndrome and spermatic cord torsion in two cryptorchid dogs. Journal of Veterinary Science. 13(2): 207-209.

31 Sanpera N., Masot N., Janer M., Romeo C. \& De Pedro R. 2002. Oestrogen- induced bone marrow aplasia in a dog with a Sertoli cell tumour. Journal of Small Animal Practice. 43(8): 365-369.

32 Schulster M., Bernie A.M. \& Ramasamy R. 2016. The role of estradiol in male reproductive function. Asian Journal of Andrology. 18(3): 435-440.

33 Scott D.W., Miller W.H. \& Griffin C.E. 2013. Endocrine and metabolic disorders. In: Muller \& Kirk's Small Animal Dermatology. 6th edn. Philadelphia: Saunders, pp.501-553.

34 Soma K.K., Tramontin A.D. \& Wingfield J.C.2000. Oestrogen regulates male aggression in the non-breeding season. Proceedings of the Royal Society of London B: Biological Sciences. 267(1448): 1089-1096.

35 Toda K., Saibara T., Okada T., Onishi S. \& Shizuta Y. 2001. A loss of aggressive behaviour and its reinstatement by oestrogen in mice lacking the aromatase gene (Cyp19). Journal of Endocrinology. 168(2): 217-220.

http://seer.ufrgs.br/ActaScientiaeVeterinariae

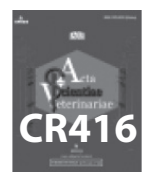

